\title{
BLENDING WITH PURPOSE: THE MULTIMODAL MODEL
}

\author{
Anthony G. Picciano \\ Professor, Graduate Center and Hunter College, City University of New York (CUNY) \\ Executive Officer of the Ph.D. Program in Urban Education \\ Graduate Center (CUNY)
}

\begin{abstract}
The purpose of this article is to propose a blending with purpose multimodal conceptual model for designing and developing blended learning courses and programs. A blended learning model is presented that suggests teachers design instruction to meet the needs of a variety of learners. Specifically, Blending with Purpose: The Multimodal Model recognizes that because learners represent different generations, different personality types, and different learning styles, teachers and instructional designers should seek to use multiple approaches including face-to-face methods and online technologies that meet the needs of a wide spectrum of students. A major benefit of multiple modalities is that they allow students to experience learning in ways in which they are most comfortable while also challenging them to experience and learn in other ways as well. Critical to this model is the concept that academic program and course goals and objectives drive the pedagogical approaches and technologies used. Issues related to definitions of blended learning, how teachers and students use technology, generational characteristics among student populations, and learning styles are examined.
\end{abstract}

\section{KEYWORDS}

Online Learning, Blended Learning, Distance Learning, Asynchronous Learning, Computer-Mediated Learning, Computer-Mediated Communications, Learning Styles, Instructional Design, Instructional Technology, Multiple Modalities

\section{INTRODUCTION}

Educators at all levels have been challenged over the past several decades by a plethora of technologies designed to assist in teaching and learning. While various technologies including television, microcomputers, presentation software, and simulation programs have been used with varying degrees of success, much of what goes on in education continues to rely on teacher-student interaction in face-toface traditional classrooms. However, with the emergence of the Internet and World Wide Web in the 1990s, online technology has begun to make serious inroads into the traditional physical classroom model. Seaman and Allen [1] after tracking online enrollments in colleges for more than five years estimated that there were approximately 3.5 million students or almost twenty percent of the total higher education population enrolled in fully online courses in American colleges and universities in 2006-2007. There are few, if any, estimates of the number of students enrolled in blended (part online and part faceto-face) courses. While it is generally believed that blended learning has reached well into the mainstream of American higher education, little data are available that document this reach. There are several reasons why so little is known about this phenomenon. 
First, many faculty do not necessarily identify themselves as teaching blended learning courses when, in fact, they are. Many college faculty, along with other segments of the general population, have become immersed in online technology and using Internet tools for instruction has become second nature. They use these tools as they would overhead projectors or blackboards. As the mystique and aura of teaching online that was present in the mid to late 1990s disappears, the faculty no longer see themselves as doing something unique and special, particularly in blended learning environments where only a portion of the class may be conducted online. As Eliot Masie, president of the Masie Center for Learning and Technology, has observed: the "e" in e-learning is disappearing and it is all just learning [2].

Second, colleges and universities are not necessarily keeping accurate records on faculty who teach blended courses. The Sloan Consortium, in collaboration with the Babson Survey Research Group, conducts annual national surveys on online learning at American colleges. The findings from these surveys represent important baseline data on student enrollments in fully online courses including the percentage and nature of colleges and universities offering these courses. While these surveys are frequently cited in studies and articles on online learning, very little data are presented on blended learning. Jeff Seaman, one of the authors of these studies, is concerned and a bit frustrated that these data are not being systematically collected at most colleges and universities. In effect, faculty might be teaching blended courses but many administrators do not necessarily know who they are or what they actually are doing in these courses. The lack of mechanisms for incorporating information on blended courses in college databases creates a situation in which a large-scale study becomes difficult to conduct and vulnerable to misinformation.

A third issue relates to definition. There is no generally accepted definition of blended learning. There are many forms of blended learning but a generally accepted taxonomy does not exist. One school's blended is another school's hybrid, or another school's mixed-mode. Furthermore, the issue is not just one of labels but the lack of agreement on a broad versus a narrow definition as well. Without a clear definition, blended learning is perceived as some nebulous combination of online and face-to-face instruction. Readers wishing to examine this issue further might refer to Graham and Robinson who in a study at Brigham Young University (BYU) identified three types of blended courses: transformative blends, enhancing blends, and enabling blends [3]. However, while identified and defined for the study's purposes, these types were not officially recognized in a formal way by the BYU administration or faculty.

Without administrative systems in place for identifying blended learning courses and without a widelyaccepted definition or taxonomy, collecting data on blended learning becomes difficult. At the same time, there is a belief that colleges and universities are not doing enough to use the available technologies to engage students in meaningful explorations of content and curricular materials [4, 5]. Marc Prensky initiated the popular "digital natives versus digital immigrants" thesis that hypothesizes a disconnect in the way younger and older generations use technology [6]. In education, students represent the younger "native" generations who are most comfortable in using technology while older faculty are the "immigrants" struggling to use it. However, while informal observation supports this theory, carefully collected data are not readily available. For example, while young people might be using technology in greater numbers than adults, especially for social activity, the quality of its application to education is unknown. It may be the case that faculty are actually more knowledgeable and use the technology more effectively for education purposes. Despite the lack of hard data and given the growing concerns about program quality, student attrition, and assessment of learning that permeates higher education, it is accepted that colleges and universities need to do more to engage students. Online technology is perceived as one of the mechanisms that will foster this engagement. 
The faculty perspective in teaching online becomes increasingly important as colleges and universities seek to make greater use of this technology in their course and program offerings. Online learning is seen as an important means of access for students who otherwise have difficulty attending traditional face-toface programs. While geographic distance was the initial incentive for colleges to offer online courses, many of which grew out of well-established distance learning programs at institutions such as the Penn State World Campus and the University of Maryland University College, time and convenience evolved as a major factor in the expansion of online learning. Colleges especially those for whom access to an education is a part of their mission, started developing online courses and programs as a convenience for their traditional students. The Allen and Seaman studies [1] referenced earlier substantiate this phenomenon in their findings that community colleges and publicly-financed colleges tend to have the largest online student enrollments and the most prolific online programs. While not all faculty have embraced the new technology, many have developed the skills necessary to teach online and do so as needed. Research suggests that many faculty blend online with face-to-face activities because they see it as beneficial to their teaching $[3,7,8]$. Late adopters of online technology might see it as a compromise when faced with the challenge of developing fully online courses. The assumption being that it might be easier to develop parts of courses for online delivery rather than entire courses. Blending also allows faculty to maintain the familiarity and security of some face-to-face contact with their students. Nevertheless, more and more faculty perceive online learning in some form as important for their students. Related to, and equally important to, this discussion is the role of college and university administrations in encouraging and supporting online instruction.

College and university administrations increasingly are dealing with institutional issues and in some cases criticisms related to tuition costs, program quality, and student attrition. Generically these are important issues, but when the online element is added, they become more complex. Judith Eaton, President of the Council for Higher Education Accreditation (CHEA), in an article directed at "presidents, chancellors, other college and university administrators, and trustees" called on administrators to become informed on quality issues related to distance learning. In the article, she goes on to state:

In the fluid and sometimes volatile environment created by [online] distance learning, we at the Council for Higher Education Accreditation (CHEA) - the national coordinating body for national, regional, and specialized accreditation—struggle to bring some order to the avalanche of information about both distance learning and quality assurance [9].

Eaton concluded her article with a warning that CHEA as well as the accreditation agencies need to provide more organization and coherence to the "plethora" of information and issues involved with quality assurance in online learning and noted that "the price for misunderstanding ... is very, very high." [9] It is clear that college and university administrators are pursuing the expansion of online learning opportunities in any case. Most have invested in course management systems such as Blackboard and have established the requisite support structure to maintain technological stability for their online learning activities. Furthermore, increasingly they are providing the necessary leadership in tying online learning to institutional goals and objectives related to the broader issues of student access to education and academic program quality.

In sum, the current environment in higher education requires the consideration of online technology in confronting a number of issues related to teaching, learning, student access and academic program quality. Blended learning increasingly is seen as one of the important pedagogical approaches that can help in this regard. The purpose of this article is to propose a blending with purpose multimodal conceptual model for designing and developing blended learning courses and programs. 


\section{DEFINING BLENDED LEARNING}

Blended learning means different things to different people. The word "blended" implies a mixture or combination. When a picture is pasted above a paragraph of text, a presentation is created that may be more informative to the viewer or reader, but the picture and text remain intact and can be individually discerned. On the other hand, when two cans of different colored paints are mixed, the new paint will look different from either of the original colors. In fact, if the new paint is mixed well, neither of the original colors will continue to exist. Similar situations exist in blended learning. The mix can be a simple separation of part of a course into an online component. For instance, a course that meets for three weekly contact hours, two hours might meet in a traditional classroom while the equivalent of one weekly hour is conducted online. The two modalities for this course are carefully separated and although they may overlap, they can still be differentiated. In other forms of blended courses and programs, the modalities are not so easily distinguishable. Consider an online program that offers three online courses in a semester that all students are required to take. The courses meet for three consecutive five week sessions. However, students do a collaborative fifteen week project that overlaps the courses. The students are expected to maintain regular communication with one another through email and group discussion boards. They also are required to meet face-to-face once a month on Saturdays where course materials from the online courses are further presented and discussed, and some sessions are devoted to group project work. These activities begin to blur the modalities in a new mixture or blend where the individual parts are not as discernable as they once were. Add to this, the increasing popularity of integrating videoconferencing, podcasting, youtube videos, wikis, blogs, and other media into class work and the definition of blended learning becomes very fluid.

In 2004, the Alfred P. Sloan Foundation funded an invitation-only workshop on blended learning. An important aspect of this workshop was to develop a working definition of the term "blended learning". The participants in this workshop had difficulty in formulating a simple definition of blended learning and the discussion alternated between a broad versus a narrow definition. Gary Miller, Associate Vice President for Outreach, and former Executive Director of The World Campus, the Pennsylvania State University, described a lengthy process at his university which resulted in a definition containing five variations of "blended learning" environments [8]. In the broadest sense, blended learning (see Figure 1) can be defined or conceptualized as a wide variety of technology/media integrated with conventional, face-to-face classroom activities. However, several workshop participants wanted to focus on a narrower definition that centered on an online component that replaced seat time in the conventional classroom (see Figure 2). The issue of a broad or narrow definition was discussed extensively and the two core elements (online and face-to-face instruction) were deemed critical to blended learning. One year later in 2005 at a second invitation only workshop, the following definition of blended learning was adopted by the participants:

1. Courses that integrate online with traditional face-to-face class activities in a planned, pedagogically valuable manner; and

2. Where a portion (institutionally defined) of face-to-face time is replaced by online activity [11].

This definition serves as a guideline and should not be viewed as an absolute, limiting declaration. Also while it was developed to refer specifically to courses, it also can apply to entire academic programs. 


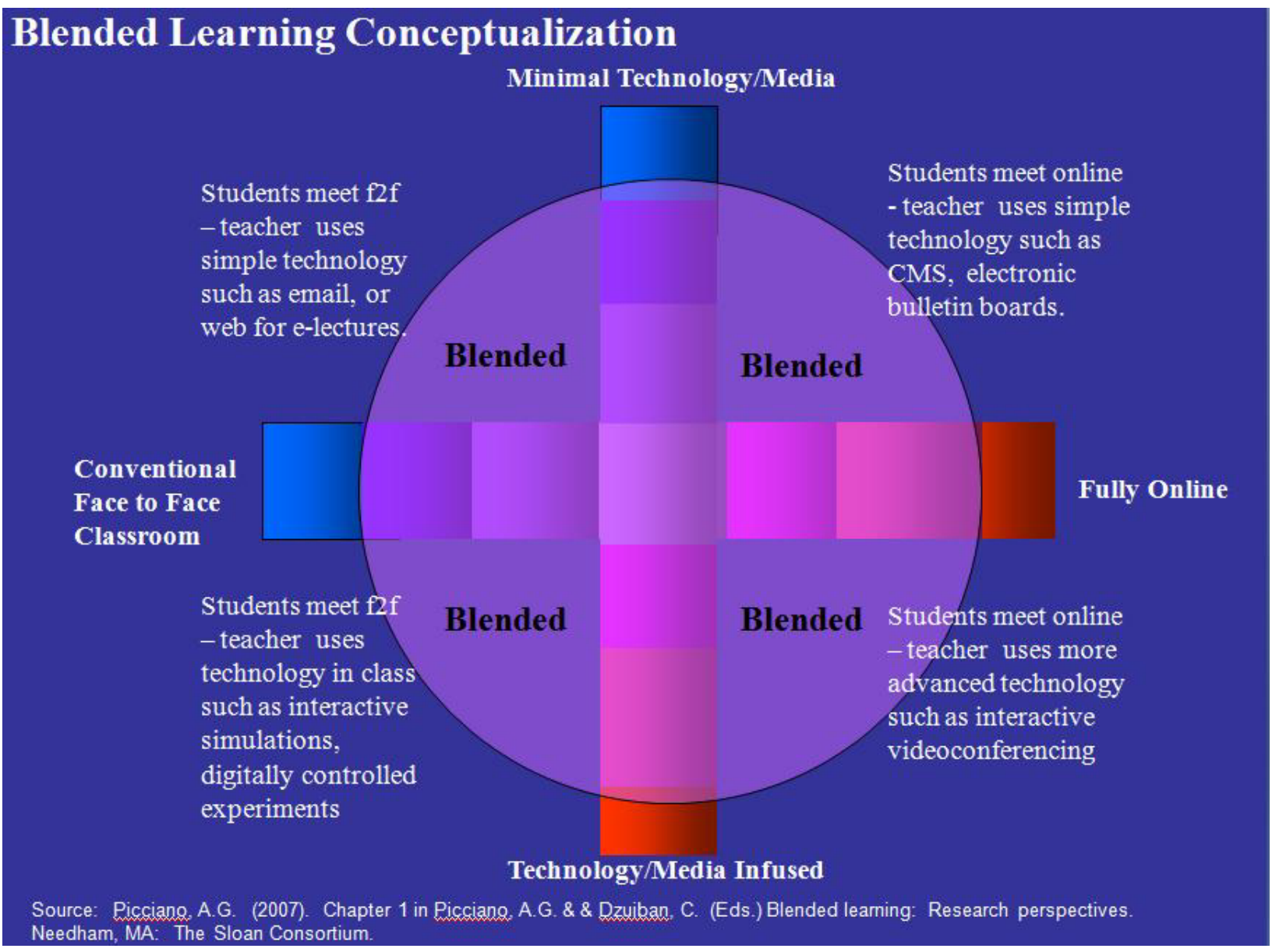

Figure 1. Broad Conceptualization of Blended Learning

\section{Blended Learning Conceptualization}

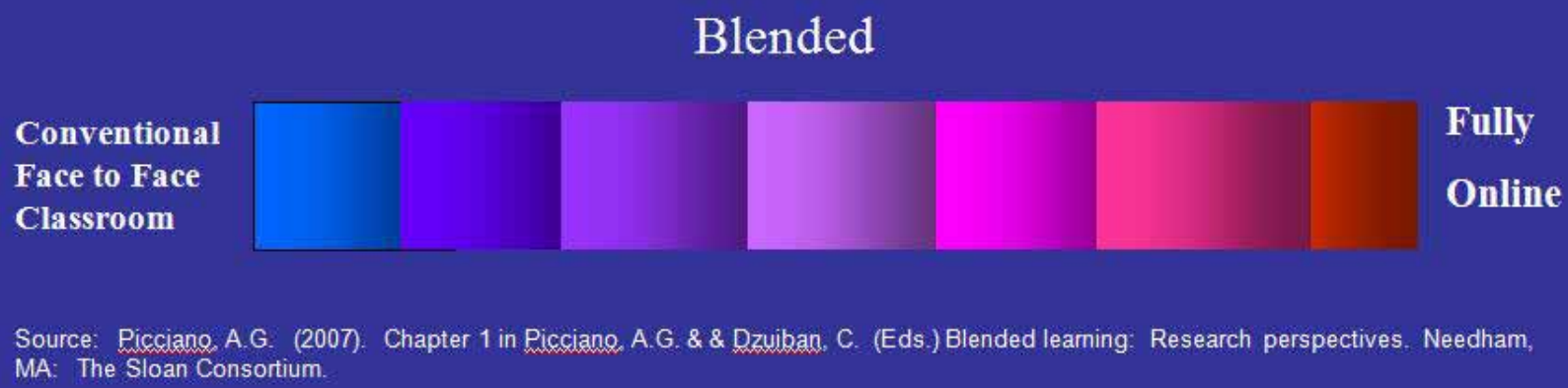

Figure 2. Narrow Conceptualization of Blended Learning 


\section{THE GENERATIONS}

Earlier in this article reference was made to the generational differences in American society related to the use of online technologies in daily life. Without a doubt, the younger generation (millennial-digital natives) use these technologies for much of their social and informational activities. Table I provides a brief description of the generations of the $20^{\text {th }}$ century. There is a legitimate concern that as the millennial generation enters college in greater numbers, faculty will need to adjust their teaching to accommodate technology-savvy students $[4,5]$.

\begin{tabular}{|l|l|l|}
\hline Name & Years of Birth & Current Age \\
\hline G.I. & $1901-1924$ & 80s and Older \\
\hline Silent & $1925-1942$ & 60 s and 70s \\
\hline Baby Boom & $1943-1960$ & 50 s and 60s \\
\hline Generation X & $1961-1981$ & 30 s and 40s \\
\hline Millennial & $1982-2002$ & 20s and Under \\
\hline \multicolumn{2}{|c|}{ Table 1. The Generations of the 20 ${ }^{\text {th }}$ Century } \\
& Source: Howe, N. \& W. Strauss. Millennials Rising: The Next Generation. \\
New York: Random House Inc., 2000.
\end{tabular}

College administrators and faculty are aware of this and are adjusting by making greater use of online technologies (as evidenced by the 3.5 million students enrolled in online courses), investing in course management systems, and expanding and converting library holdings to electronic media. However, while the millennials will be enrolling in colleges in greater numbers, they will not represent the vast majority of students for many years to come.

\begin{tabular}{|l|r|r|r|r|r|r|r|}
\hline \multicolumn{1}{|c|}{ Age } & $\mathbf{1 9 9 0}$ & $\mathbf{1 9 9 5}$ & $\mathbf{2 0 0 0}$ & $\mathbf{2 0 0 2}$ & $\mathbf{2 0 0 5}$ & $\mathbf{2 0 1 0}$ & $\mathbf{2 0 1 4}$ \\
\hline Total & 13,819 & 14,262 & 15,312 & 16,612 & 17,350 & 18,816 & 19,470 \\
\hline 14 to 17 years & 177 & 148 & 145 & 202 & 201 & 216 & 215 \\
\hline 18 and 19 years & 2,950 & 2,894 & 3,531 & 3,571 & 3,705 & 4,067 & 3,951 \\
\hline 20 and 21 years & 2,761 & 2,705 & 3,045 & 3,366 & 3,456 & 3,848 & 3,845 \\
\hline 22 to 24 years & 2,144 & 2,411 & 2,617 & 2,932 & 3,143 & 3,384 & 3,686 \\
\hline 25 to 29 years & 1,982 & 2,120 & 1,960 & 2,102 & 2,374 & 2,724 & 2,913 \\
\hline 30 to 34 years & 1,322 & 1,236 & 1,265 & 1,300 & 1,290 & 1,399 & 1,573 \\
\hline 35 years plus & 2,284 & 2,747 & 2,749 & 3,139 & 3,181 & 3,178 & 3,287 \\
\hline
\end{tabular}

Table 2. Total Fall Enrollment in Degree-Granting Institutions by Age: Years 1990 through 2014 (in thousands) Source: U.S. Department of Education, National Center for Education Statistics. Digest of Education Statistics (NCES 2006-030), 2006.

Table 2 provides student enrollments by age from 1990 through 2005 and projections through 2014. In examining this data closely, it is obvious that older students (25 years plus) make up a sizable percentage of the total student population and will continue to do so for the foreseeable future. In 2005, 40\% percent of the higher education student population was 25 years and older, and almost $60 \%$ was 22 years and older. Whether seeking advanced graduate degrees, completing undergraduate programs from which they dropped out when they were younger, upgrading their professional and job skills, or simply interested in life-long learning and intellectual growth (a major phenomenon that accelerated in the latter part of the $20^{\text {th }}$ century), Americans of all ages were engaged in higher education. The phenomenon of the non- 
traditional (older) student started in the 1950s with the G.I Bill of Rights and the inclusion of returning World War II veterans in higher education. It has continued unabated ever since. In many college classes, especially in large public institutions and community colleges with diverse populations, students continue to represent a broad spectrum of age groupings. Course delivery should be designed to address a variety of needs and learning styles rather than specifically targeting a particular segment.

\section{LEARNING STYLES}

Student learning can be influenced by many factors including the technology and media used for delivery. Over the decades, however, the various technologies that have dominated American society have not necessarily altered how students learn. A good example is television. Vladimir Zworykin, one of the individuals credited with inventing the "tube" in the 1920s and 30s, hoped that his work would result in a technology that would among other things be an aid to education. In the 1950s, television proliferated throughout American society. By the1960s, classrooms throughout the country were being equipped and reconfigured for television. In many or in most of these classrooms, the television was rarely or never used. At first, it was generally believed that there just wasn't enough quality educational content available. But even after major investments by entities such as the Public Broadcasting System and the Annenberg Foundation, video materials while enhanced and integrated, were not a substitute for traditional instruction. For the most part, television was a passive technology with little direct interaction that required the teacher to provide the interaction and engagement with the material in order to be successful. However, another important factor was that people learn in different ways. Visual stimulation is important for some but not for others. The same is true for classroom interaction; some students thrive in active learning environments while others learn just as well in less active environments. These differences are well documented in much of the learning styles literature that has evolved in cognitive and educational psychology. For example, Lin, Cranton \& Bridglall remind us that much of the work of Carl Jung in the early 1900s on personality types (e.g., extroversion v. introversion) is still applicable to learning environments whether face-to-face or online [12]. The extrovert may prefer active, highly collaborative environments while the introvert would prefer less interaction and less collaboration. This suggests that instruction should be designed to allow both types of individuals - the outgoing social organizer as well as the introspective reflective observer- to thrive.

Probably one of the better-known theories on learning styles relates to the "multiple intelligences" work of Howard Gardner [13]. Dating from the late 1970s and early 1980s, Gardner posited that intelligence is not a singular entity but is made up of multiple entities in different proportions used by individuals to understand and to learn about the world. Gardner identified eight basic intelligences (linguistic, logical/mathematical, spatial, musical, bodily kinesthetic, interpersonal, intrapersonal, naturalistic) that influence how people learn and lead to individual preferences in learning situations. The implications for learning are significant and Gardner recommends that instruction should use multiple modalities that allow learners to engage in ways they prefer/have interest/have ability in while also challenging them to learn in other ways where they have less preference, interest or ability. Gardner's work also addresses the concern that too much of teaching and learning is linguistically-based (reading, writing, speaking) and that the other intelligences need to be better utilized.

More recently, cognitive science is making major contributions to the learning styles literature. Interdisciplinary in nature, cognitive science draws from psychology, biology, neuroscience, computer science, and philosophy to try to understand the workings of the mind as well as cognitive development which forms the foundation for how people learn and acquire knowledge. Much of the research in cognitive science and learning styles continues increasingly is being influenced by physiological research on brain function. Current cognitive science research suggests that students learn in different ways 
depending upon a number of factors including their age, learning stimuli, the pace of instruction, etc. It also suggests that learning is a dynamic process that may evolve and change from one classroom to another, from one subject to another, and from one day to another [14]. Finally, cognitive science suggests that multiple intelligences and mental abilities do not exist as yes-no entities but within continua from which the mind blends the manner in which it responds to and learns from the external environment and instructional stimuli. Conceptually this suggests a framework for a multimodal instructional design that relies on a variety of pedagogical techniques, deliveries, and media.

\section{BLENDING WITH PURPOSE}

Figure 3 depicts the Blending with Purpose model that derives from the discussions above on blended learning technology, generations, and learning styles. It posits that pedagogical objectives and activities should drive the approaches that faculty use in instruction. It also suggests that blending these objectives, activities, and approaches within multiple modalities might be most effective for and appeal to a wide range of students. This model presents six basic pedagogical objectives and activities and appropriate approaches for achieving them. Of course, there may be other objectives that can be added where appropriate. Most importantly, instructors need to consider carefully their objectives and understand how to apply the technologies and approaches that will work best for them. A quick review of the objectives used in the model and their concomitant technology will be helpful in understanding the overall model.

Content is perhaps the primary driver of instruction and there are many ways in which content can be delivered and presented. Increasingly, course management systems such as Blackboard, WebCT, or Moodle provide the basic content delivery mechanisms. CMS software handles the delivery of a variety of media including text, video and audio. Multi-user virtual environments (MUVE) and gaming are also evolving and playing more of a role in providing instructional content. In providing and presenting content, the Blending with Purpose model suggests that multiple technologies and media be utilized.

The Blending with Purpose model posits that instruction is not always just about learning content or a skill but is also about supporting students socially and emotionally. Perhaps more readily recognized for younger K-12 students, social and emotional development is an important part of anyone's education. Faculty who have taught advanced graduate courses know that the students, even at this advanced level, frequently need someone with whom to speak whether for understanding a complex concept or providing advice on career and professional opportunities. While fully online courses and programs have evolved to the point where faculty can provide some social and emotional support where possible and appropriate, this might best be provided in a face-to-face (F2F) mode. 


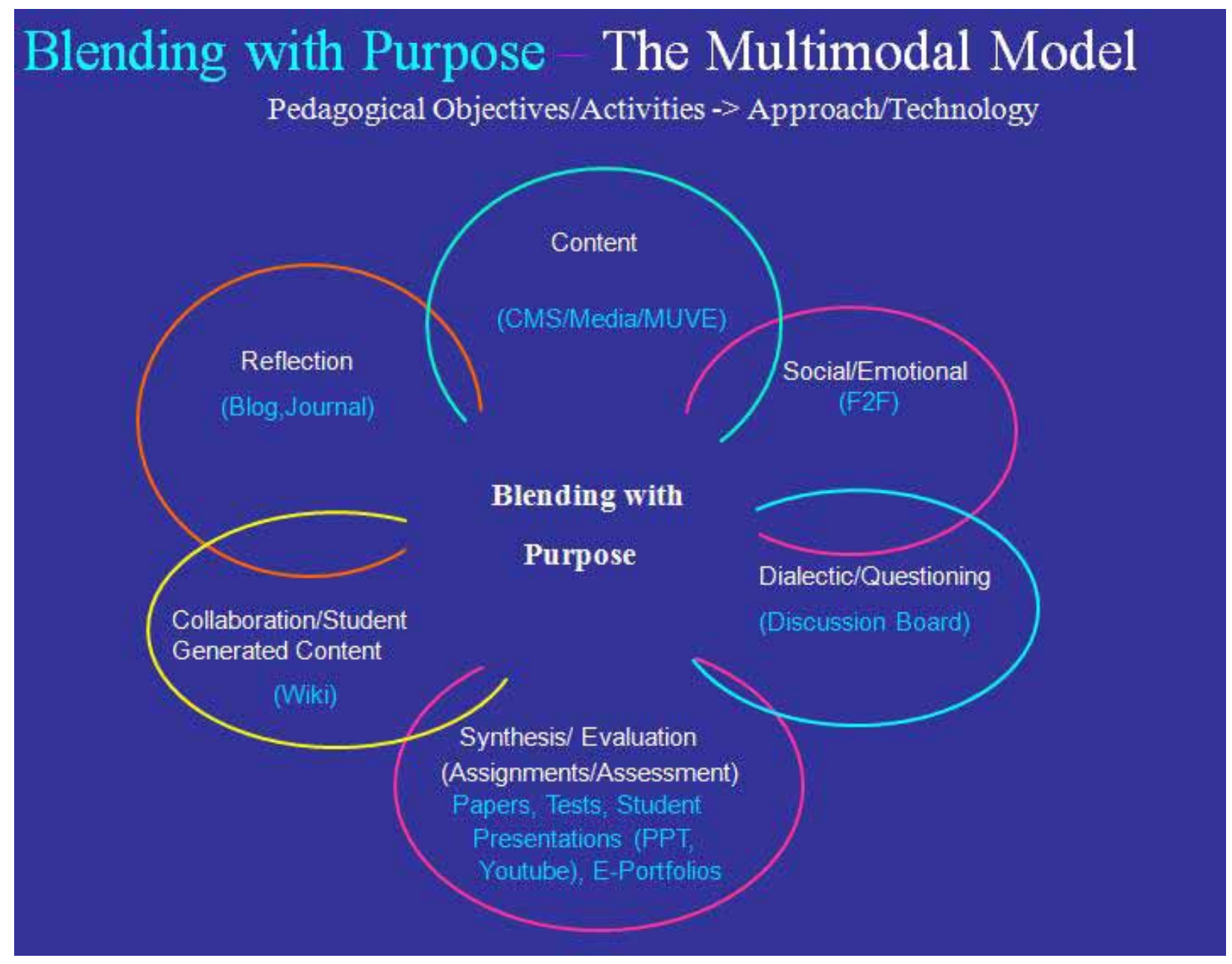

Figure 3. Blending with Purpose: The Multimodal Model

Dialectic/questioning is an important activity that allows faculty to probe what students know and to refine their knowledge. The Socratic Method remains one of the major activities used in instruction and many successful teachers are proud of their ability to stimulate discussion by asking the "right" questions that help students think critically about a topic or issue. In many cases, these questions serve to narrow the discussion down to very specific "points" or aspects of the topic or issue and are not meant to be openended "anybody can say anything at anytime" activities. For dialectic and questioning activities, a simple to use, threaded electronic discussion board is as or more effective than most other approaches. A wellorganized discussion board activity generally seeks to present a topic or issue and have students respond to questions, provide their own perspectives while also evaluating and responding to the opinions of others. The simple, direct visual of the "thread" also allows students to see how the entire discussion or lesson has evolved. In evaluations of online learning activities, the main interactive tool for many courses has been and continues to be discussion-board activity centered on a specific topic.

Incorporating reflection can be a powerful pedagogical strategy. There is an extensive body of scholarship on the "reflective teacher" and the "reflective learner". While reflection can be a deeply personal activity, the ability to share one's reflection with others can likewise be most beneficial. Pedagogical activities that require students to reflect on what they are learning and to share their reflection with their teachers and fellow students are viewed very positively. Blogs and blogging, whether as group activities or for 
individual journaling activities, are evolving as appropriate tools for students reflecting on what is being learned and on other aspects of course activities.

Collaborative learning has been evolving for decades. In face-to-face classes, group work has grown in popularity and has become a staple in many course activities. In the past, the logistics and time needed for effective collaboration in face-to-face classes were sometimes problematic. However, with email and other electronic communications, some of these logistical problems were alleviated. More recently, wikis have grown significantly in popularity and are becoming a staple in group projects and writing assignments. Furthermore, unlike group work that typically ends up on the instructor's desk when delivered in paper form, wikis allow students to generate content that can be shared with others during and beyond the end of a semester. Papers and projects developed with wikis can pass seamlessly from one group to another and from one class to another.

Finally and perhaps the most important component of the model is synthesizing, evaluating and assessing learning. CMSs and other online tools provide a number of mechanisms for assisting in this regard. Papers, tests, assignments and portfolios are among the major methods used for assessing student learning and increasingly are being done electronically. Essays and term projects pass back and forth between teacher and student without ever being printed on paper. Oral classroom presentations are giving way to youtube videos and podcasts. The portfolio is evolving into an electronic multimedia presentation of images, video, and audio that goes far beyond the three-inch paper-filled binder. Weekly class discussions that take place on discussion boards or blogs provide the instructor with an electronic record that can be reviewed over and over again to examine how students have participated and progressed over time. They also are most helpful to instructors in assessing their own teaching and in reviewing what worked and what did not work in a class. In sum, online technology allows for a more seamless sharing of evaluation and assessment activities. It also provides an on-going record that can be referred to over and over again by both students and teachers.

The six components of the model as described above should blend together in an integrated manner that appears as seamless as possible for students. As mentioned earlier in this paper, blending should be more a mixture of different colors of paint to create new colors or new learning environments rather than cutting and pasting visibly separate combinations of images, text and other media or material. Furthermore, not every course must incorporate all of the activities and approaches of the model. The pedagogical objectives of a course should drive the activities and hence the approaches. Not every course needs to require students to do group work. Not every course should rely entirely on reflective activities. Finally, beyond examining individual courses, faculty and instructional designers should consider examining their entire academic program to determine which components best fit which courses to serve cohesively overall programmatic goals and objectives.

\section{CONCLUSION}

The purpose of this article was to examine a blending with purpose multimodal conceptual model for designing and developing blended learning courses and programs. In this article, a blended learning model was presented that suggests that teachers design instruction to meet the needs of a variety of learners. Specifically, the Blending with Purpose: The Multimodal Model recognizes that because learners represent different generations, different personality types and different learning styles, teachers and instructional designers should seek to try to use multiple approaches including face-to-face and online technologies to meet the needs of a wide spectrum of students. Furthermore, it posits that a major benefit of multiple modalities is that they allow students to experience learning in ways in which they are most comfortable while also challenging them to experience and learn in other ways as well. Critical to this 
model is the concept that academic program and course goals and objectives drive the pedagogical approaches and technology used.

\section{REFERENCES}

1. Allen, I. E. \& J. Seaman. Online Nation: Five Years of Growth in Online Learning. Needham, MA: The Sloan Consortium, 2007. http://www.sloan-c.org/publications/survey/pdf/online nation.pdf. Accessed June 23, 2008.

2. Masie, E. E-Learning, the Near Future. In G. Piskurich (Ed.), The AMA Handbook of E-Learning, 411-418, 2003.

3. Graham, C. \& R. Robinson. Realizing the Transformational Potential of Blended Learning: Comparing Cases of Transforming Blends and Enhancing Blends in Higher Education. In A. G. Picciano \&C. Dzuiban (Eds.), Blended Learning: Research Perspectives. Needham, MA: The Sloan Consortium, 2007.

4. Florida, R, G. Kaimal, D. Oblinger \& L. Blessing. How generations X and Y (Millenials) Will Reshape Higher Education. Society for College and University Planning Virtual Seminar, 2003. http://www.scup.org/profdev/archive cds/gen x-y.html. Accessed June 30, 2008.

5. Rogers, M., D. Oblinger \& J. Hartman. Education in Exponential Times: How TechnologyEnabled Change is Reshaping Higher Education. Society for College and University Planning Webcast, 2007.

6. Prensky, M. Digital Natives, Digital Immigrants (Parts I and II). On the Horizon, NCB University Press 9(1): 2001. http://www.marcprensky.com/ Accessed May 26, 2005.

7. Vignare, K. Blended Learning: Using ALN to Change the Classroom: Will it Work? In A. G. Picciano \& C. Dzuiban (Eds.), Blended Learning: Research Perspectives. Needham, MA: The Sloan Consortium, 2007.

8. Kaleta, R., K. Skibba \& T. Joosten. Discovering, Designing, and Delivering Hybrid Courses. In A. G. Picciano \& C. Dzuiban (Eds.), Blended Learning: Research Perspectives. Needham, MA: The Sloan Consortium, 2007.

9. Eaton, J. S. Assuring Quality in Distance Learning. The CHEA Chronicle 3(3): 2000. http://www.chea.org/Chronicle/vol3/no3/focus.html. Accessed June 30, 2008.

10. Miller, G. Blended Learning and Sloan-C. Posting to the Official Website of the 2005 Sloan-C Summer Workshop held in Victoria, British Columbia, June 30 2005.

11. Laster, S., G. Otte, A. G. Picciano \& S. Sorg. Redefining Blended Learning. Presentation at the 2005 Sloan-C Workshop on Blended Learning, Chicago, IL, April 18, 2005.

12. Lin, L., P. Cranton \& B. Bridglall. Psychological Type and Asynchronous Written Dialogue in Adult Learning. Teachers College Record 107(8): 1788-1813, 2005. http://www.tcrecord.org ID Number: 12096. Accessed: January 25, 2008.

13. Gardner, H. Frames of Mind: The Theory of Multiple Intelligences. New York: Basic Books, 1983.

14. Willingham, D. What is Developmentally Appropriate? American Educator 32(2): 34-39, 2008.

\section{ABOUT THE AUTHOR}

Anthony G. Picciano is a professor and executive officer of the Ph.D. Program in Urban Education at the Graduate Center of the City University of New York (CUNY). He is also a professor in the graduate program in Education Leadership at Hunter College, the doctoral program in Interactive Pedagogy and Technology at the Graduate Center (CUNY), and the interdisciplinary program in Communication and Culture at the CUNY School of Professional Studies. He has forty years of experience in education administration and teaching, and has been involved in a number of major grants from the U.S. Department of Education, the National Science Foundation, IBM, and the Alfred P. Sloan Foundation. 
In 1998, Dr. Picciano co-founded CUNY Online, a multi-million dollar initiative funded by the Alfred P. Sloan Foundation that provides support services to faculty using the Internet for course development. Currently he serves on the Board of Directors of the Sloan Consortium. His major research interests are education policy and leadership, Internet-based teaching and learning, and multimedia instructional models.

Dr. Picciano has authored numerous articles and eight books including Data-Driven Decision Making for Effective School Leadership (2006, Pearson), Educational Leadership and Planning for Technology, $4^{\text {th }}$ Edition (2005, Pearson), Distance Learning: Making Connections across Virtual Space and Time (2001,Pearson), and Educational Research Primer (2004, Continuum). His most recent book was coedited with Chuck Dzuiban and is entitled, Blended Learning: Research Perspectives (2007, Sloan Consortium). In 2007, Dr. Picciano completed a national study, with Jeff Seaman on the extent and nature of online learning in American school districts. It is one of the first studies to collect data on and compare fully online and blended learning in K-12 schools. He is currently collecting data for a follow-up study on this topic. 